\title{
A SYSTEM DESIGN OPTIMIZATION MODEL FOR INTEGRATED NATURAL RESOURCE CONSERVATION AND DEVELOPMENT IN AN AGRICULTURAL COMMUNITY
}

\author{
Barlow, Thomas (1); \\ Biddanda, Mandappa (1); \\ Mendke, Samarth (1); \\ Miyingo, Emmanuel (2); \\ Sicko, Anabel (1); \\ Papalambros, Panos Y. (1); \\ Chien, Cheng-Chun (1); \\ O'Neal, William (1) \\ 1: University of Michigan; \\ 2: Makerere University
}

\begin{abstract}
Integrated Natural Resource Conservation and Development (INRCD) Projects are efforts at worldwide locations to promote economic development of local communities consistent with conservation of natural resources. This umbrella term includes Integration Conservation and Development Projects (ICDPs) introduced by the World Wide Fund to combine social development and conservation $\mathrm{s}$ through the use of socio-economic investments, and the Integrated Natural Resource Management (INRM) research and development efforts that have employed a systems approach for quantitative modeling and optimization. In the spirit of the INRCD framework, we describe the development of a system-level agriculture and energy model comprising engineering and economic models for crop, irrigation, and energy subsystem designs for a community in Central Uganda. The model architecture is modular allowing modifications for different system configurations and project locations. We include some initial results and discuss next steps for system optimization, refining model assumptions, and modeling community social benefits as drivers of such projects.
\end{abstract}

Keywords: Optimisation, Sustainability, Integrated Natural Resource Conservation and Development (INRCD), Integrated Conservation and Development Projects (ICDP), Constraint modelling

\section{Contact:}

Sicko, Anabel

Optimal Design Laboratory, University of Michigan

Mechanical Engineering

United States of America

asicko@umich.edu

Cite this article: Barlow, T., Biddanda, M., Mendke, S., Miyingo, E., Sicko, A., Papalambros, P. Y., Chien, C.-C., 


\section{INTRODUCTION}

The UN Sustainable Development Goals include conservation of land, water, and other resources as a top priority for sustainable development (UNDP, 2015). Conservation and development seem to be conflicting goals, especially as traditional conservation initiatives adopt a non-participatory "fines and fences" approach. The World Wide Fund for Nature first introduced the concept of integrated conservation and development projects (ICDP) in the mid 1980s, aspiring to combine social development and conservation goals through the use of socio-economic investment tools (Hughes and Flintan, 2001). Theory, tools and methods evolved considerably since the 1980s, creating opportunities to revisit and expand existing approaches to ICDP design. Integrated Natural Resource Management (INRM) studies have employed a systems thinking approach suitable for quantitative modelling and optimization (Bekalo et al., 2010).

In this paper we advocate a modular system design optimization framework as a decision support tool for the planning and operation of projects combining the ICDP and INRM approaches, which collectively we call Integrated Natural Resource Conservation and Development (INRCD) Projects. A recent review of INRCD projects identified the use of quantitative tools to support decision making as an important factor for project success (Rajski et al., 2021). A system design optimization tool can serve this role; its important attributes are modularity to allow tailoring to specific projects, inclusion of community needs, and an objective that maximizes community benefits.

For a concrete demonstration, we consider an 'Agriculture-Energy' (Ag-En) project, namely, a community that cultivates crops, requires water for irrigation and community use, and operates a local electricity grid (microgrid) that draws power from several sources and distributes it for household and irrigation needs. In the following sections, we describe a particular Ag-En model representative of a community in Central Uganda along with the many modelling assumptions, and provide some example results for subsystem optimization. The overall system optimization and the development of a social benefit objective function, besides profit, are left as future work.

\section{SYSTEM DESIGN MODEL}

The Ag-En system design model outlined in this paper comprises two main subsystems (i) water supply and crop cultivation and (ii) energy supply by a microgrid drawing from a variety of energy sources. The water supply provides the required crop irrigation and household water. The microgrid powers the irrigation water pumping system and households within the community. A stochastic weather model is input to the system, characteristic of the ever-present uncertainty in agriculture. In Figure 1, the microgrid subsystem consists of photovoltaic panels, batteries, and a back-up diesel generator; weather is an input and energy supply for water pumping and household use is the target to be met. The irrigation and crop subsystem comprises pumping equipment, irrigation equipment and layout design, and land allocation to different crops. Weather, soil, and an external water supply are inputs, while crop yield and energy demand are outputs.

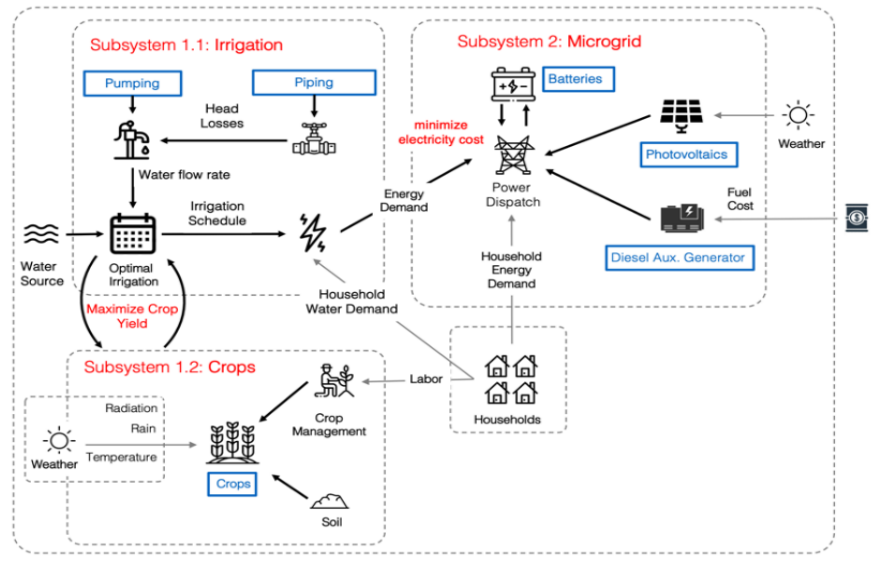

Figure 1. Agriculture-Energy system model flow diagram 


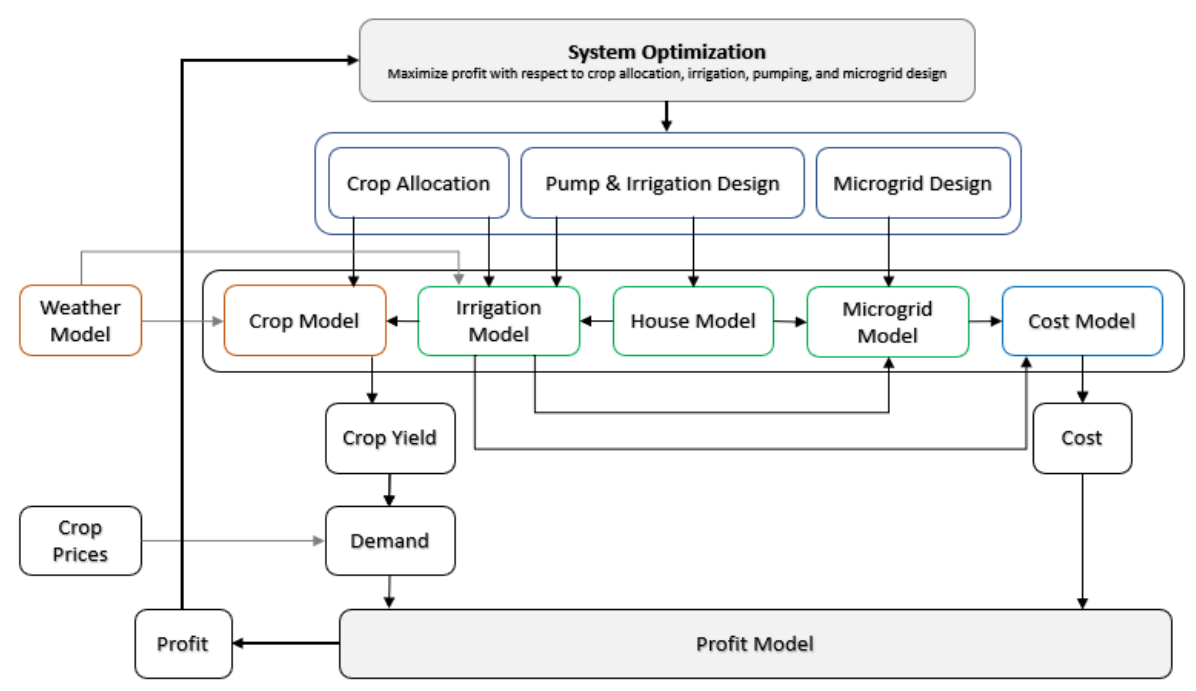

Figure 2. Agriculture-Energy project optimization model

Besides technical functionality, the system also has economic functionality. Economic considerations include capital equipment, labour, irrigation, and other farming costs, and crop revenue. Capital equipment is installed and operated along with the associated costs. Labour is supplied from the households for cultivation. Crop yields are sold in the market providing income. Management provides decisions on crop allocation in the given land based on local soil and weather conditions, crop rotation for sustainability, and crop market prices.

In a system design optimization framework, see Figure 2, initial decisions (system design variables) are made on crop allocation, pump design, and microgrid design. These feed into the crop, irrigation, and microgrid models which in turn compute crop yields and system costs. Market demand and cost then go into a profit maximization objective for the system, and the optimizer iterates on the initial decisions. Project location affects the key inputs (system parameters): weather, soil, market, and labour rates. Within each outer optimal design iteration, there are two optimal control operations. The microgrid power dispatch operation determines how to meet the energy demand during a time interval by allocating the supply from the existing energy sources in order to minimize the total cost of energy supply. Similarly, the water scheduler operation determines irrigation schedules and household water supply in order to maximize crop yield.

A typical system optimization strategy will use the Individual Disciplinary Feasible (IDF) architecture for system design coordination (Papalambros and Wilde, 2017). The information flow is shown in Figure 3, where $\mathrm{f}, \mathrm{g}$, and $\mathrm{h}$ are the system objectives, inequality and equality functions, respectively, and $\mathrm{x}$ and $\mathrm{y}$ are the system design and linking variables, respectively. The system comprises two subsystems, crop-irrigation and microgrid, with maximum profit as overall system objective. The subsystems are linked through balancing supply and demand, and also through their contribution to overall system cost in the objective. As discussed in Section 4, the preliminary results reported here do not include complete system optimization.

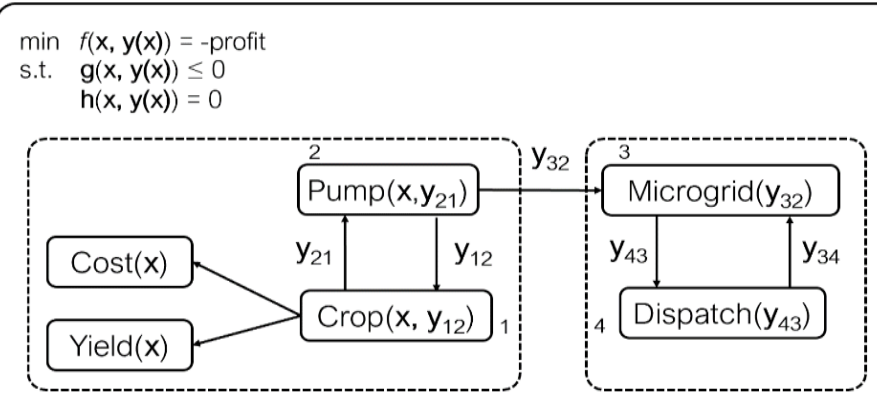

Figure 3. System optimization with a generic IDF architecture (Papalambros and Wilde 2017) 
In its simplest form, the outlined Ag-En system has seven design variables to be optimized: size of diesel generator, and number of batteries and solar panels in the microgrid; number of impeller stages in the pump, and pipe diameters of the irrigation submain and lateral branches in the irrigation piping; and percent field use per crop for maize, rice, soybean, and open non-cultivated (no-crop) land. The system objective is to maximize profit for the community with constraints for social and environmental considerations, where profit $=($ revenue $)-($ cost $)$. Revenue is calculated from crop sales and the yield $\left(a_{i}\right)$ dedicated to a specific crop, the crop price at harvest, and the yield of crop $\mathrm{i}(\mathrm{i}=1, \ldots, \mathrm{n})$ :

$$
\begin{aligned}
& \text { revenue } \text { rev }_{\text {crop }}+\text { labor }_{\text {noncrop }}= \\
& =\sum_{i=1}^{n} \text { Price }_{i} * \text { Yield }_{i}(\text { Weather })+\text { wage } *\left(\text { hours }_{\text {total }}-\text { hours }_{\text {crop }}\left(a_{i}\right)\right), \\
& \text { Yield }_{i}=a_{i}\left(\text { Area } * \text { Yield }_{\text {dry }}(\text { Weather })\right) .
\end{aligned}
$$

The system cost is estimated as

$$
\operatorname{cost}=\operatorname{cost}_{\text {energy }}+\operatorname{cost}_{\text {pump }}+\operatorname{cost}_{\text {crop }}+\operatorname{cost}_{\text {irr }},
$$

where irrigation and pump costs were split to allow for modularity. Other cost details are omitted for brevity.

Several legacy software are used in assembling the system model, notably, AquaCrop OS (AQOS) (Foster et al., 2017) developed by the Food and Agriculture Organization (FAO) to simulate yield response to water; the Simple Soil-Water Balance (SWB) model (Rao et al., 1988); the Deficit Irrigation Toolbox (DIT) developed by the Technical University of Dresden (Schütze and Mialyk, 2019); the LARS-WG Stochastic Weather Generator (Semenov and Barrow 2002); and the Hybrid Microgrid Optimal Design (Hymod) model (Alvarez et al. 2018, Ruiz, 2020).

\section{MODEL ELEMENTS AND ASSUMPTIONS}

We describe some key parts of the system model and the associated assumptions.

\subsection{Community Setting}

The project location is a rural community in Central Uganda. Market access is not modelled at present. Household energy demand varies hourly but not daily. The household model parameters include hourly water and energy demand, number of people, and available labour. The community daily household energy demand curve per hour is assumed fixed throughout the day. We use the average household load profile for Ugandan rural villages based on a 2009 study (Prinsloo, 2016), see Figure 4. The model adjusts, compressing or expanding the curve, based on system parameters.

Water demand is modelled similarly, but in the absence of data for African locations we adapted data from Spain and used the average of the four curves in Figure 5 as baseline for energy demand due to warm water consumption (Fuentes et al., 2018).

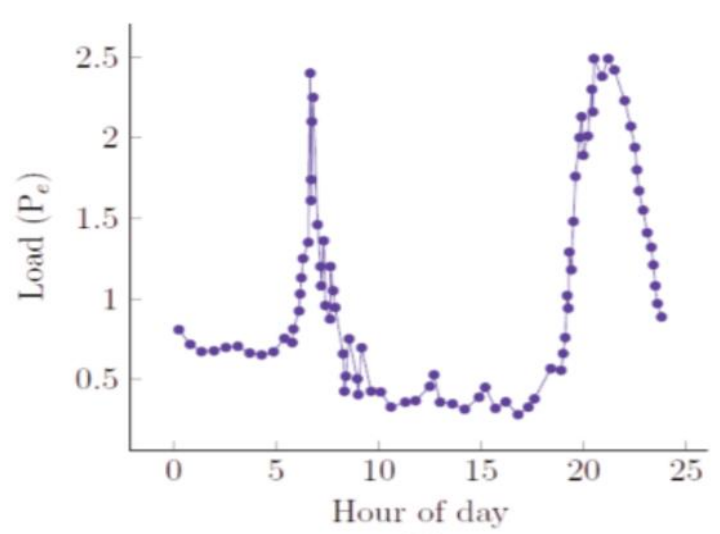

Figure 4:. Household energy demand, in kW; Prinsloo et al. (2016) from Tinarwo (2009) 


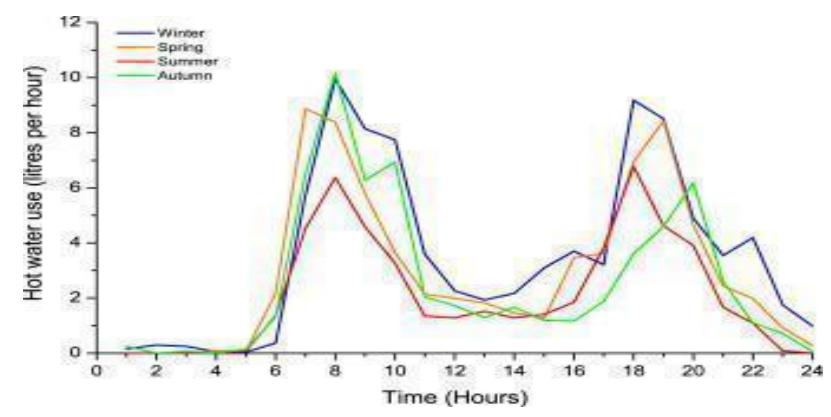

Figure 5. Warm water consumption in Spain (Sprei, 2002)

\subsection{Microgrid}

We implemented a modification of the Hymod model (Ruiz, 2020) that minimizes cost of energy with an hourly dispatching strategy. The modified model uses solar panels, batteries, and a diesel generator, see Figure 6. The weather model generates hourly irradiance and temperature as climatological data model parameter inputs reflecting site location and equipment used. The model is simulated over a length of one year. Energy dispatch is controlled hourly with the design of the controller fixed. There is no central electricity grid and the microgrid distribution losses are negligible. To reduce optimization run time due to hourly calculations of energy and to extend the capability to longer simulations, each day in a month was assumed to be the same.

We added a cost estimate for the diesel generator and the generator size as a new local variable. Battery, generator, and solar panel types were fixed, although the model can accommodate different types that can be eventually included in the optimization. Capital cost of the diesel generator is modelled as a linear function of generator size, which is not true but sufficient for our present purpose (Schienbein et al., 2004).

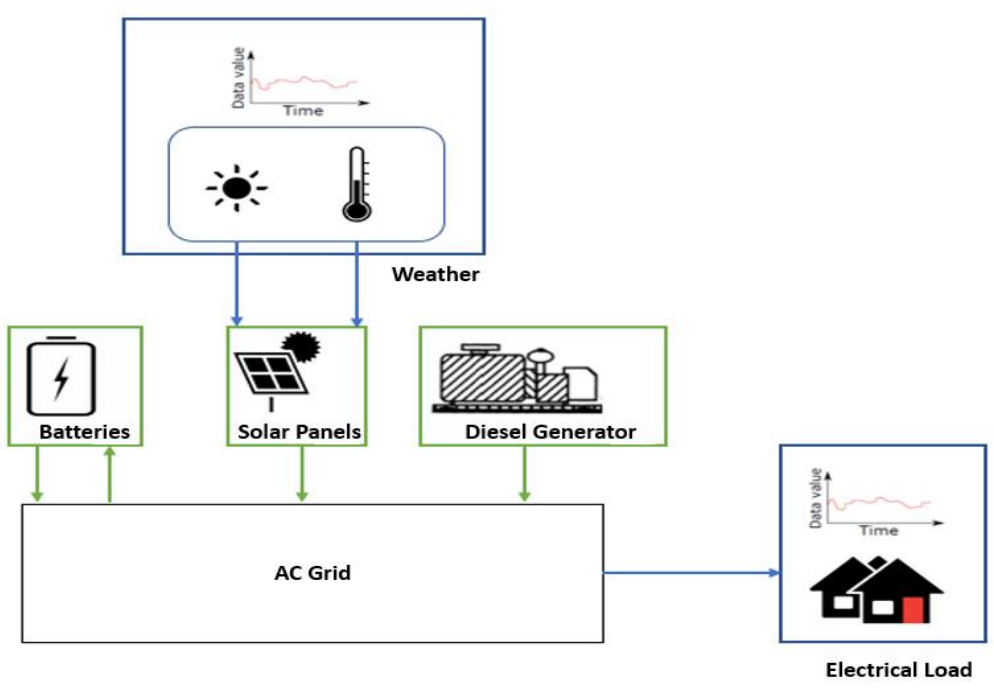

Figure 6. Modified Hymod operation scheme

\subsection{Crop Yield and Revenue}

We chose three common crops in Uganda, maize, rice, and soybeans, with a no-crop land option available. This allows the optimizer to shrink the field if irrigation and energy costs are higher than the revenue of the crop. We assumed best practices for crop and field management; any deviations would result in yield reduction at increased cost. All labour is assumed to be manual with simple hand tools. A rudimentary fertilization model is used. The crop subsystem consists of irrigation and crop as two separate models. The crop model is further divided into a yield model and a cost model.

The yield model aims to balance accuracy with simplicity, and incorporates the Deficit Irrigation Toolbox, AquaCrop OS, and the Simple-Water Balance (SWB) legacy models referenced earlier. The DIT toolbox was used to generate crop yield estimates for maize, rice, and soybeans. To avoid the long computation times of AQOS in the scheduler optimization, when there is a water deficit, we use SWB to calculate yield. The SWB model calculates only the percent of maximum yield, and so we 
perform a relatively fast AQOS run to compute the yield in tons per hectare without any constraints on the water usage as input to the crop revenue calculation:

$$
\text { rev }_{\text {crop }}=\sum_{i=1}^{n=3} \text { Price }_{i}\left[\frac{\text { USD }}{\text { ton }}\right] * a_{i}\left(\text { Area }[\text { hect }] * \text { Yield }_{\text {dry }}\left[\frac{\text { tons }}{\text { hect }}\right]\right) .
$$

The parameters in the yield computation are data on crop, field, soil profile, groundwater, weather, and simulation time periods. Maize and soybeans are default crops in AQOS and were left unchanged but for rice we used the parameters given in the rice development simulation of Prathumchai et al. (2018). AQOS has few options for field management, and most are not used in sub-Saharan Africa, and so we used default values for field management parameters, namely, no mulching, bunds or weed management. Red and brown soil types were used in the simulation with their profiles created using information from the literature (Fungo et al., 2011; Minai, 2015; Veenstra et al., 2009), which was provided in standard sand-clay content and we then converted it into general soil types. Veenstra (2009) provided soil horizons from a mapping in Central Uganda. We used a soils calculator from the United States Department of Agriculture, Natural Resources Conservation Services for Soils to calculate each layer's soil type (Natural Resources Conservation Service, 2020). The groundwater was assumed at 20-25m below surface based on the Africa Groundwater Atlas (Owor et al., 2018).

Simulation data consists of the time period, initial conditions, off-season conditions, and field data for calibration. We assumed the time period to be one year. The other parameters were assumed to be negligible or irrelevant for this simplified model. Weather details are provided in Section 3.5. We used maize and rice crop prices from historical data in the FAO's FPMA tool (FAO, 2020a) and soybean price from Macrotrends (2020). Monthly prices from January 2020 to December 2020 in Central Uganda were used with the Winter-Holt method (FAO, 2020a) to forecast the prices of rice and maize.

\subsection{Irrigation and Pumping}

A single pump type and family is used operating at its optimal flow rate by the scheduler. The irrigation layout has main, submains, and lateral branches. The household piping layout comprises a single main pipe connected from the water tank to the house. The irrigation can be sprinkler, drip, or basin type. Drip irrigation, also referred to as low-flow, trickle, or micro-irrigation in non-commercial settings, is considered more sustainable because it uses 20-50 percent less water than conventional systems (EPA, 2020b). The irrigation and pumping sub-system have been modelled by considering drip irrigation and submersible pumps. The groundwater is pumped by the submersible pump and stored in the water tank placed at sufficient height to meet the operating pressure of the drip irrigation system. The water from the tank is supplied to meet the total water demand for agricultural and household operations.

The irrigation model consists of equipment design (layout and pump station), controller (daily scheduler and hourly scheduler converter), and the energy demand calculation. The irrigation layout is based on a square field with a main line, submain pipes, and laterals, with rows spaced at $40 \mathrm{~cm}$. The system head is calculated by measuring the major head losses due to friction in the pipes based on Darcy-Weisbach Equation (Brown, 2012) and the minor head losses due to presence of fittings and valves in the overall piping layout. Only the crop area has irrigation, and so the piping length is a function of the crop area. The total head loss is used to create a system curve with varying levels of flow based on a maximum flow. This system curve is used in the pump station model to calculate the optimal flow rate for the pump. The layout is considered fixed in this model instantiation.

We calculate the optimal flow rate using the system demand curve and the pump performance curve as derived, for example, from Pumpmakers (2020) where flow rate is predicted from curve fitting of the pump impeller stages and head. A single pump performance curve is then created from a single pump stage and an array of head losses. The intersection between this single pump performance curve and the system curve gives the optimal pump operation parameters for a given flow rate and head.

The optimal schedule is determined using the DIT model modified slightly to act as a subsystem within the larger model. The daily irrigation event maxima are dictated by the pump operating flow rate. The season maximum is set as a constant that depends on the maximum water legally available to use. We assumed the pump operates always at optimal efficiency, and the only variable in the scheduler is the time when the pump is turned on or off. The daily optimizer was calculated using the GET-OPTIS built into DIT optimizer (Schütze et al., 2012). The daily water schedule is then converted into the hourly energy schedule needed for the energy subsystem. To get more robust results in the final profit 
calculation with the relatively simple system model, we use three different hourly watering schedules: when the sun produces the most solar energy, when the evaporation is minimal, and at a given starting time; then we select the most effective schedule for system optimization. The hourly schedule is converted into energy demand based on pump efficiency, volume pumped, and system head:

$$
E_{e}=E_{h} *\left(\frac{100}{\eta}\right)=V * H *\left(\frac{\rho * g}{3600 * 10^{3}}\right) *\left(\frac{100}{\eta}\right),
$$

where $E_{e}$ is electrical energy supplied to the pump motor [kWh], $E_{h}$ is hydraulic energy [kWh], $V$ is volume of water pumped [m3, $H$ is total pumping head [m], $\rho$ is density of water $[1,000 \mathrm{~kg} \mathrm{~m}-3], \mathrm{g}$ is standard gravity $[9.8 \mathrm{~m} \mathrm{~s}-2$, and $\eta$ is motor pump efficiency [\%].

\subsection{Weather Model}

We use the LARS-WG Stochastic Weather Generator with 30 years of regional historical data. Using site input data for time in years, Julian calendar date, maximum temperature $\left({ }^{\circ} \mathrm{C}\right)$, minimum temperature $\left({ }^{\circ} \mathrm{C}\right)$, precipitation $(\mathrm{mm})$ and solar radiation $(\mathrm{MJm}-2$ day-1), LARS-WG generates synthetic weather time-series data with the same statistical characteristics as the observed weather data (Semenov et al., 2002). Using the weather data generated by LARS-WG, we calculate hourly irradiance and temperature in Uganda that follow daily temperature curves and solar radiation curves, respectively (Okello et al., 2011). These hourly data are inputs to the energy model, and the hourly data along with daily minimum and maximum temperature, solar irradiance, and precipitation are inputs for the crop model, along with the reference evapotranspiration (mm day-1) used in the crop model to calculate evapotranspiration for each crop.

The required climate parameters are daily minimum and maximum temperatures, irradiance, precipitation, and reference evapotranspiration. The parameter values are calculated before each optimization run using a stochastic model generated by sampling from a normal distribution where the mean and standard deviation are based on historic data from the region. The daily reference evapotranspiration is calculated using the Penman-Monteith equation (FAO 2020b) with vapor pressures and psychrometric constants estimated using the max and min temperatures:

$$
E T_{0}=\frac{0.408 \Delta\left(R_{n}-G\right)+\gamma\left(\frac{900}{T+273}\right) u_{2}\left(e_{s}-e_{a}\right)}{\Delta+\gamma\left(1+0.34 u_{2}\right)}
$$

where $E T_{0}$ is the reference evapotranspiration [mm day-1], $R_{n}$ is net radiation at crop surface [MJ m-2 day-1], $G$ is soil heat flux density [MJ -2 day-1], $T$ is air temperature at $2 \mathrm{~m}$ height $\left[{ }^{\circ} \mathrm{C}\right], u_{2}$ is wind speed at $2 \mathrm{~m}$ height $[\mathrm{m} \mathrm{s}--1], e_{s}$ is saturation vapor pressure $[\mathrm{kPa}], e_{a}$ is actual vapor pressure $[\mathrm{kPa}], e_{s}-e_{a}$ is saturation vapor pressure deficit $[\mathrm{kPa}], \Delta$ is the slope vapor pressure curve $\left[\mathrm{kPa}{ }^{\circ} \mathrm{C}-\right.$ $1]$, and $\gamma$ is the psychrometric constant $\left[\mathrm{kPa}{ }^{\circ} \mathrm{C}-1\right]$.

\subsection{Cost Models}

Cost models for crop and irrigation are relatively straightforward and omitted here for brevity. Cost components are fixed capital equipment costs for the irrigation and microgrid components, and variable costs for water supply, seeds, fertilizer, and labour. Some information on water tariffs in Uganda can be found in Motoma (2007). Cost models for the microgrid were briefly discussed in Section 3.2; cost is a combination of total yearly system costs and a total yearly system emissions penalty, both depending on the elements comprising the grid. The fixed costs are amortized over the life span of the components assuming a loan at a standard interest rate is needed to finance the initial investment. This ensures that the yearly profit represents a realistic scenario.

\section{PRELIMINARY SUBSYSTEM RESULTS}

The fully assembled system presents several optimization challenges: (i) the two subsystems in Figure 3 are coupled optimal design and control or co-design problems (Papalambros and Wilde, 2017), since the microgrid dispatcher and the irrigation scheduler are both optimal control problems that must be executed for each design generated during the system optimization iterations, see also Seidel et al. (2015); (ii) the weather 'parameters' are sets of stochastic quantities and accounting for stochasticity in an 'equivalent' deterministic problem is not obvious; (iii) the overall system model likely has discontinuities that are not evident when incorporating the legacy codes. Thus, the effectiveness of 
gradient-based methods is unclear while the computational cost of non-gradient methods may be prohibitive.

These challenges suggest that further analysis must proceed with caution, exploring the problem starting with many simplifications and adding complexity gradually by removing simplifications. In this spirit, some preliminary results are reported here under many simplifications as first steps. The two subsystems shown in Figure 3, crop-irrigation and microgrid, are separated and studied individually under the assumption that the microgrid will meet fully the demand from the irrigation. No full system optimization results using the IDF architecture are reported here.

\subsection{Crop-Irrigation Subsystem Parametric Study}

For the crop-irrigation subsystem, as a first step we consider the maximum yield and thus maximum profit problem with a fixed price of electricity supplied externally, such as from a power grid. Crop allocation percentages for maize, rice, soybeans, and no-crop; the number of impeller stages; and the diameters of lateral and submain pipes are design decision variables. We consider only drip irrigation starting at 6am each morning for a flat, one-hectare field. Using the same row spacing but different spacing between each plant of three crops, we estimated the number of plants per hectare to be 75,000 , 170,000 , and 330,00 for three crops maize, rice, and soybeans, respectively. The maximum annual supply of water is capped at $200 \mathrm{~mm}$, and the external cost of electricity is $0.182 \mathrm{USD} / \mathrm{kWh}$.

The irrigation model calculates optimal head loss, pump flow rate, and efficiency for the given pump and irrigation variables; DIT calculates the maximum yield for a particular irrigation and crop allocation with seasonal and daily water usage as constraints. Revenue from crop sales and subsystem costs determine profit, thus completing one outer subsystem iteration. For the optimization study, we tested seven different initial points as shown in Table 1; every two rows represent a set of the initial point and the optimal result from the optimizer. The results reflect higher price of rice dominating crop allocation under the assumptions of this example. This is consistent with common practices pushing for mono-cultivations to maximize profit without accounting for conservation considerations.

Table 1. Crop-irrigation subsystem optimization results

\begin{tabular}{|c|c|c|c|c|c|c|}
\hline $\begin{array}{l}\text { Maize, Rice, } \\
\text { Soybean, No-crop } \\
{[\%]}\end{array}$ & $\begin{array}{l}\text { No. of } \\
\text { Impeller } \\
\text { Stages }\end{array}$ & $\begin{array}{l}\text { Lateral, } \\
\text { Submain } \\
\text { Pipe Diameter } \\
\text { (cm) }\end{array}$ & $\begin{array}{l}\text { Yield per Crop } \\
\text { [tonne/hectare] }\end{array}$ & $\begin{array}{l}\text { Total } \\
\text { Revenue } \\
\text { (USD) }\end{array}$ & $\begin{array}{l}\text { Total } \\
\text { Cost } \\
\text { (USD) }\end{array}$ & $\begin{array}{l}\text { Total } \\
\text { Profit } \\
\text { (USD) }\end{array}$ \\
\hline $80,20,0,0$ & 30 & $1.78,7.62$ & & & & \\
\hline $0,100,0,0$ & 30 & $1.52,5.08$ & $0,13.5,0,0$ & 12095 & 2572 & 9523 \\
\hline $0,100,0,0$ & 35 & $2.28,8.89$ & & & & \\
\hline $0,100,0,0$ & 35 & $1.52,5.08$ & $0,13.5,0,0$ & 12095 & 2596 & 9499 \\
\hline $0,0,100,0$ & 40 & $3.55,9.65$ & & & & \\
\hline $0,100,0,0$ & 40 & $1.52,5.08$ & $0,13.5,0,0$ & 12095 & 2615 & 9480 \\
\hline $50,50,0,0$ & 43 & $3.55,10.16$ & & & & \\
\hline $0,100,0,0$ & 43 & $1.52,8.35$ & $0,13.5,0,0$ & 12095 & 2646 & 9449 \\
\hline $0,50,50,0$ & 45 & $3.55,11.4$ & & & & \\
\hline $0,100,0,0$ & 45 & $1.52,5.08$ & $0,13.5,0,0$ & 12095 & 2652 & 9443 \\
\hline $30,10,30,30$ & 50 & $1.78,13.9$ & & & & \\
\hline $0,100,0,0$ & 50 & $1.52,5.08$ & $0,13.5,0,0$ & 12095 & 2734 & 9361 \\
\hline $25,25,25,25$ & 50 & $1.78,12.7$ & & & & \\
\hline $0,100,0,0$ & 53 & $1.52,5.08$ & $0,13.5,0,0$ & 12095 & 2870 & 9225 \\
\hline
\end{tabular}

These initial results require further testing to get more confidence in terms of global optimality.

\subsection{Microgrid Subsystem Optimization}

The subsystem design variables are the numbers of solar panels and batteries and the generator size. The modified Hymod model uses the irrigation energy demand and household energy demand as inputs, and it computes a dispatch strategy that minimizes microgrid cost. Branch and Cut (Albert, 1999) and SQP (Papalambros and Wilde, 2017) algorithms were used for optimization and the resulting minimized cost and dispatch strategy were inputs to the profit model. The SQP optimizer terminated more robustly. The 
design layout recommended is four sets of three modules at $0.33 \mathrm{~kW}$ each. The minimized cost of the setup is USD 6,969. The solar panel cost is USD 1,674, the batteries cost is USD 859, and the diesel generator cost is USD 4,330. The diesel generator cost has the largest impact on system cost and likely is an overestimate due to the behaviour of the optimization modelled monthly.

\subsection{Discussion and Limitations}

The results are consistent with expected insights; for example, given all the simplifications, rice dominates when water is plentiful and there is little variation in profit. The needs of one household over one year were considered in order to obtain these first results. More realistic results will need to consider (i) multiple households over a 5-7year period, (ii) more accurate variable costs, (iii) better estimates of local community water and energy demand patterns, (iv) pumping from other sources than ground water, sprinkler irrigation, and centrifugal pumps, and (v) replacing the diesel generator with occasional power grid use and/or wind energy. More importantly, to explore the trade-offs between conservation and development a social value objective should replace profit. Other factors of INRCD success, such as community involvement and training in project maintenance and management (Rajski and Papalambros, 2021) are beyond the current state of the model and will require significant new research.

\section{CONCLUSION}

A system design optimization model for an INRCD Project is quite complicated and presents both modelling and optimization challenges; these include the multidisciplinary nature of the problem calling for diverse expertise in a variety of knowledge domains, the lack of good data, and the stochastic, nonlinear, mixed-discrete, and combinatorial nature of the models. A large number of assumptions, as pointed out throughout, allowed development of the particular instantiation here as an illustration. Some next steps include (i) further testing of the subsystem models with different parameters and some assumptions relaxed; (ii) integrated system optimization studies; (iii) development of an appropriate social value objective for the local community that encompasses criteria beyond profit.

\section{ACKNOWLEDGEMENTS}

This work is part of the Design Society's AFRICA-DESIGN initiative. The Society's support is gratefully acknowledged. We thank Prof. Dr. Niels Schütze, Institute of Hydrology and Meteorology, TU Dresden, for his valuable modelling advice and assistance.

\section{REFERENCES}

Albert, S (1999). Solving Mixed Integer Linear Programs Using Branch and Cut Algorithm. MS thesis, Mathematics, North Carolina State University, 1999.

Alvarez, S.R., Oviedo, J.E. and Gil, A.A. (2018). "Hymod: A Software for Hybrid Microgrid Optimal Design." 15th International Conference on Electrical Engineering, Computing Science and Automatic Control, IEEE, New York City, New York. https://doi.org/10.1109/ICEEE.2018.8533914

Bekalo, I., Ochola, W.O. and Sanginga, P.C. (2010), Managing natural resources for development in Africa: a resource book. University of Nairobi Press, Nairobi, Kenya.

Brown, G.O. (2012). "The History of the Darcy-Weisbach Equation for Pipe Flow Resistance", Environmental and Water Resources History, ASCI. Available online: https://ascelibrary.org/doi/10.1061/40650(2003)4.

EPA (2020a). Greenhouse Gases Equivalencies Calculator. Accessed on 8 Dec. 2020. https://www.epa.gov/energy/greenhouse-gases-equivalencies-calculator-calculations-and-references

EPA (2020b). Watersense: Adding Microirrigation to Your Services: A Mini-Guide for Irrigation Professionals. [online] Available at: https://www.epa.gov/sites/production/files/2018-05/documents/ws-outdoorsmicroirrigation-prosguide.pdf. (Accessed on 8 Dec. 2020).

FAO (2020a). GIEWS FPMA Tool - monitoring and analysis of food prices. [online] Available at: https://fpma.apps.fao.org/giews/food-prices/tool/public/\#/dataset/domestic. (Accessed on 8 Dec. 2020)

FAO (2020b). FAO Penman-Monteith Equation. [online] Available at: http://www.fao.org/3/X0490E/x0490e06.htm\#fao penman monteith equation (Accessed on 8 Dec. 2020)

Foster, T., T. Foster, N. Brozović, A.P. Butler, C.M.U. Neale, D. Raes, P. Steduto, E. Fereres, T.C. Hsiao (2017). "AquaCrop-OS: An open-source version of FAO's crop water productivity model." Agricultural Water Management, Vol. 181, pp.18-22. https://doi.org/10.1016/j.agwat.2016.11.015 
Fuentes, E., Arce, L. and Salom, J. (2018). “A review of domestic hot water consumption profiles for application in systems and buildings energy performance analysis." Renewable and Sustainable Energy Reviews, Vol. 81, pp. 1530-1547. https://doi.org/10.1016/j.rser.2017.05.229

Fungo, B., Grunwald, S., Tenywa, M. M., Vanlauwe, B. and Nkedi-Kizza, P. (2010), "Lunnyu Soils in the Lake Victoria basin of Uganda: Link to Toposequence and Soil type.” Online Journal of Earth Sciences, Vol. 4 No. 2, pp. 63-71. https://doi.org/10.3923/ojesci.2010.63.71

Hughes, R. and Flintan, F. (2001). Integrating conservation and development experience: a review and bibliography of the ICDP literature. International Institute for Environment and Development, London.

Macrotrends (2020). Soybean Prices - 45 Year Historical Chart. [online]. Available at: https://www.macrotrends.net/2531/soybean-prices-historical-chart-data'>Soybean\%20Prices\%20$\% 2045 \% 20$ Year\%20Historical\%20Chart\&lt;/a> (Accessed on 8 Dec 2020)

Minai, J. O. (2015). Assessing the spatial variability of soils in Uganda. PhD Dissertation, Purdue University.

Motoma, R.I.P. (2007). Modelling a Water Conserving Tariff for Kampala Uganda. MS Thesis, Loughborough University.

Okello, D., Banda, E. and Mubiru, J. (2011). “Availability of Direct Solar Radiation in Uganda.” ISES Solar World Congress, Kassel, Germany, 2011. https://doi.org/10.18086/swc.2011.24.22

Owor, M., Tindimugaya, C., Brown, L., Upton, K., Ó Dochartaigh, B.É. and Bellwood-Howard, I. (2018). Africa Groundwater Atlas: Hydrogeology of Uganda. [online] British Geological Survey. Available at: http://earthwise.bgs.ac.uk/index.php/Hydrogeology_of_Uganda (Accessed November 30, 2020.)

Papalambros, P.Y. and Wilde, D.J. (2017). Principles of Optimal Design: Modeling and Computation, Cambridge University Press, Cambridge, England.

Prathumchai, K., Nagai, M., Tripathi, N. K. and Sasaki, N. (2018). "Forecasting Transplanted Rice Yield at the Farm Scale Using Moderate-Resolution Satellite Imagery and the AquaCrop Model: A Case Study of a Rice Seed Production Community in Thailand.” ISPRS International Journal of Geo-Information, Vol. 7 No.2, p. 73. https://doi.org/10.3390/ijgi7020073

Prinsloo, G., Dobson, R., and Brent, A. (2016). "Scoping exercise to determine load profile archetype reference shapes for solar co-generation models in isolated off-grid rural African villages.” Journal of Energy in Southern Africa, Vol. 27 No. 3, pp. 11-27. https://doi.org/10.17159/2413-3051/2016/v27i3a1375

Pumpmakers (2020). PM Pumpmakers GmbH, Sankt Veit an der Glan, Austria. Available at: https://pumpmakers.com/en (Accessed 30 Nov. 2020)

Rajski, P. and Papalambros, P.Y. (2021). "Integrated Natural Resource and Conservation Development Project: A Review of Success Factors from a Systems Perspective."Proceedings of the Design Society ICED21, Gothenburg, Sweden (this volume).

Rao, N.H., Sarma, P. and Chander, S. (1988). "Irrigation scheduling under a limited water supply", Agricultural Water Management, Vol. 15 No. 2, pp.165-175. https://doi.org/10.1016/0378-3774(88)90109-6

Ruiz, S. (2020). Hymod: A Software for Hybrid Microgrid Optimal Design. Available at: https:/www.mathworks.com/matlabcentral/fileexchange/66123-hymod-a-software-for-hybrid-microgridoptimal-design, MATLAB Central File Exchange. (Accessed 30 Nov. 2020.)

Schienbein, L. A., Balducci, P. J., Nguyen, T. B., Brown, D. R., DeSteese, J. G. and Speer, G. A. (2004). Avoiding Distribution System Upgrade Costs Using Distributed Generation, PennWell Pub., Tulsa, OK.

Schütze, N. and Mialyk, O. (2019). "Deficit Irrigation Toolbox: A new tool to improve crop water productivity and food security under limited water resources." 21st EGU General Assembly, Vienna, Austria.

Schütze, N., de Paly, M. and Shamir, U. (2012). "Novel simulation-based algorithms for optimal open-loop and closed-loop scheduling of deficit irrigation systems." Journal of Hydroinformatics, 14 (1): 136-151. https://doi.org/10.2166/hydro.2011.073

Seidel, S.J., Schütze, N., Fahle, M., Mailhol, J.-C. and Ruelle, P. (2015). “Optimal Irrigation Scheduling, Irrigation Control and Drip Line Layout to Increase Water Productivity and Profit in Subsurface DripIrrigated Agriculture.” Irrigation and Drainage, 64, 501-518. https://doi.org/10.1002/ird.1926

Semenov, M.A. and Barrow, E.M. (2002). LARS-WG: A Stochastic Weather Generator for Use in Climate Impact Studies. User Manual, Hertfordshire, UK, 0-27.

Sprei, F., 2002. Characterization of power system loads in rural Uganda. MS Thesis, Lund University of Technology, Lund, Sweden.

Tinarwo, D., 2009. Design of village power and microgrids for rural areas of Zimbabwe with specific attention to voltage regulation on low voltage meshed distribution grids. Kassel University Press, Kassel, Germany.

UNDP (2015). Sustainable Development Goals. [online] Available at:

https://www.undp.org/content/undp/en/home/sustainable-development-goals.html. (Acc. 8 Dec. 2020)

USDA (2020). Natural Resources Conservation Service. Soil Texture Calculator. Available at: https://www.nrcs.usda.gov/wps/portal/nrcs/detail/soils/survey/?cid=nrcs142p2_054167 (Acc. 30 Nov. 2020)

Veenstra, J., Dembe, D., Nsamba, J., Wasko, L., Burras, L., Nonnecke, G., Orum, B., Downie, S. and Cox, R. (2009). "Mapping Soils in Central Uganda." Soil Survey Horizons, Vol. 50 No. 1, pp. 31-34. https://doi.org/10.2136/sh2009.1.0031 